\title{
Inviting complementary perspectives on situated normativity in everyday life
}

\author{
Pim Klaassen • Erik Rietveld • Julien Topal
}

Published online: 3 June 2009

C The Author(s) 2009. This article is published with open access at Springerlink.com

\begin{abstract}
In everyday life, situations in which we act adequately yet entirely without deliberation are ubiquitous. We use the term "situated normativity" for the normative aspect of embodied cognition in skillful action. Wittgenstein's notion of "directed discontent" refers to a context-sensitive reaction of appreciation in skillful action. Extending this notion from the domain of expertise to that of adequate everyday action, we examine phenomenologically the question of what happens when skilled individuals act correctly with instinctive ease. This question invites exploratory contributions from a variety of perspectives complementary to the philosophical/ phenomenological one, including cognitive neuroscience, neurodynamics and psychology. Along such lines we try to make the normative aspect of adequate immediate action better accessible to empirical research. After introducing the idea that "valence" is a forerunner of directed discontent, we propose to make progress on this by first pursuing a more restricted exploratory question, namely, 'what happens in the first few hundred milliseconds of the development of directed discontent?'
\end{abstract}

Keywords Directed discontent - Instinctive normative action ·

Philosophy and neuroscience $\cdot$ Valence $\cdot$ Wittgenstein

\footnotetext{
P. Klaassen

Department of Philosophy, University of Amsterdam, Nieuwe Doelenstraat 15, 1012 CP Amsterdam, The Netherlands

E. Rietveld $(\bowtie)$

Department of Philosophy, Fellow in Philosophy, Harvard University, Emerson Hall, Cambridge, MA 02138, USA

e-mail: rietveld@fas.harvard.edu

J. Topal

Department of Social and Political Sciences, European University Institute, Via dei Roccettini 9, I-50014 San Domenico di Fiesole (FI), Italy
} 


\section{Introduction}

In everyday life we often act adequately, yet without deliberation. For instance, when standing in an elevator we "instinctively" obtain and maintain an appropriate distance from others. Such immediate action implies a notion of normativity that is very basic, namely distinguishing adequate from inadequate, correct from incorrect, or better from worse in the context of a particular situation (Rietveld 2008b). Elsewhere we have developed Wittgenstein's insight, formulated in his "Lectures on Aesthetics" (1978; henceforth LA), that a specific type of affective behavior called 'directed discontent' is essential for getting things right in unreflective skillful action (Rietveld 2004; Klaassen et al. 2006; Klaassen 2006; Rietveld 2008b). In contrast to what its title suggests, Wittgenstein's focus of attention in that work is not what are traditionally considered to be aesthetical-philosophical concerns. Instead, he elaborates on situations in which experts in some trade, such as architecture or tailoring, act in accord with relevant rules and do so with an "instinctive" fluency.

According to Wittgenstein (LA, pp. 11 \& 13), the central concept to be explained concerning aesthetic practices is "appreciation" of objects against the background of the craftsman's socio-cultural practice. Wittgenstein presents directed discontent as a subtle and context-sensitive reaction of appreciation. Wittgenstein (LA, p. 13) introduces this concept in a core example describing the engaged reaction and firstperson experience of an architect who instinctively corrects the design of a door by responding immediately to this perceived object (in its context). These appreciations have an evaluative character and are expressed in his absorbed ways of selecting and acting. It is important to distinguish this type of reactions from "judging". While the latter is more detached, deliberative and propositional, appreciation of an object by an expert craftsman is engaged, immediate, non-deliberative, and non-propositional. Appreciation shows itself in the way of (re)acting (LA, p. 7). In unreflective action objects are typically appreciated on-line, that is to say, in the process of the craftsman's working at improving them. Importantly, appreciation has a normative character: it generally concerns the correctness of an object for the appreciator within its context. Moreover, because contexts are normally complex, it is not possible to make fully explicit what appreciation consists of (LA, p. 7).

In sum, Wittgenstein shows that skill and appreciation are crucial for understanding how expert craftsmen act correctly yet without deliberation. Elsewhere (Klaassen et al. 2006; Rietveld 2008b) we have suggested that directed discontent can be seen as a paradigmatic expression of the normative aspect of embodied cognition in skillful action, that is, of "instinctive normative action" or "situated normativity"2. In this paper we will first of all make clear that instinctive normative action is not only a crucial phenomenon for understanding

\footnotetext{
${ }^{1}$ To avoid misunderstanding, let us briefly expand on our use of the words "instinctive" and "instinct" here. Wittgenstein (1993; original text from 1937-1938) criticizes the use of the word "intuition" with respect to skilful behavior. He prefers to use instinct in that context (De Lara 2003), probably to stress the bodily basis of this type of know-how. Importantly, for him instinctive reactions of this type can be socially acquired and controlled. They are flexible in the sense that these reactions are sensitive to the context, including its socio-cultural dimension. We will use "instinctive" in this distinctive and broad sense too.

${ }^{2}$ We will use the terms 'instinctive normative action' and 'situated normativity' interchangeably.
} 
architects and comparable expert craftsmen at work, but also for many situations of everyday action. This should further establish the importance of investigating this phenomenon.

We will suggest that if one wants to fully understand the complex phenomenon of situated normativity, one needs to engage several complementary perspectives. In this paper we make a first attempt to open up and connect a variety of perspectives on instinctive normative action. This brings us to build on insights from such various disciplines as philosophy, psychology, neuroscience, and (neuro)phenomenology. Together these perspectives should help in advancing an answer to this paper's central question: What happens when a skilled individual acts correctly with instinctive ease?

This question is formulated rather unspecifically by purpose. As explicated in our methodological note below ("Methodological note on integrating perspectives"), we would like to invite exploratory complementary contributions from a multiplicity of philosophical and empirical disciplines. In line with this we formulate an unspecific, yet inclusive, question. Given the current state of affairs in science, it is clear in advance that our central question cannot be answered in full. Hence our two modest aims are to make progress from the perspective of phenomenology and to propose a strategy for making this complex question better accessible to empirical research. To these aims we will primarily focus on the notion of "valence", as introduced by Varela and Depraz (2005). These authors use the concept of valence in the context of their observation that the first constitutive moments of an experience are characterized both by event-related affect and movement. In order to emphasize the combined presence of these two aspects, they call valence a "motion-affect" (Varela and Depraz 2005, p. 71; cf. Gallagher and Varela 2003). ${ }^{3}$ As will become clear, valence can be understood to be a precursor to directed discontent and the first moment of an event-related instinctive normative act.

This paper proceeds as follows. Before engaging in the multi-perspectival investigation of situated normativity, in "Instinctive normative action and the scope of this endeavor" the scope of our endeavor will be clarified by means of the presentation of two cases that are illustrative for the importance and ubiquity of this phenomenon. We stress that it is not only our understanding of the normativity of unreflective expert action that could benefit from phenomenogical and empirical investigations of this complex phenomenon, but also our understanding of many more quotidian situations. In "Methodological note on integrating perspectives" and "Neurophenomenology and dynamical systems theory: a brief introduction" we will pay attention to some methodological considerations. Thereafter we will turn to the notion of valence in "A precursor to directed discontent: valence". Lastly, in "A strategy for investigating instinctive normative action empirically" we will articulate a strategy for investigating instinctive normative action empirically.

\footnotetext{
${ }^{3}$ In this paper "motion-affect" will be treated as synonymous with "affective behavior", because both are used to characterize the simultaneously behavioral and affective responsiveness to the demands of the particular situation, such as is manifested by Wittgenstein's craftsmen in action (cf. Rietveld 2008b).
} 


\section{Instinctive normative action and the scope of this endeavor}

Although the notion of 'directed discontent' was used by Wittgenstein to describe how craftsmen such as architects and tailors can do their work well unreflectively, we contend that it can help us understand the normative aspect of many more quotidian situations. We will show that Wittgenstein's case of seeking the right word while writing a text is an example of directed discontent in everyday life ("Directed discontent in everyday engaged reflection"). Moreover, we will suggest that situated normativity plays a role in everyday social interaction as well ("Instinctive normative action in everyday social interaction").

Instinctive normative action in everyday social interaction

Klaassen (2006) argues that people's quotidian interaction with others can often be understood as falling within the category of instinctive normative action. Let us illustrate this.

Take the situation that Mary is having an intimate yet cheerful conversation with her friend Lucas, and that they are expecting to meet a third friend, Andra. Mary is in a good mood. Then, when Andra enters the room where Mary is chatting with Lucas, Mary instantly and unexpectedly notices in Andra's facial expression that she feels miserable. In a wink her mood, expression and attitude change and this suddenly emerging aspect of her friend's condition affects her subsequent activity. From one readiness-to-act (continuing the nice conversation with a friend) Mary shifts to another (comforting Andra, inquiring what is wrong, etcetera). (Cf. Klaassen 2006.)

With regard to several relevant characteristics this example resembles the type of action Wittgenstein elaborates on in his LA and that we have called instinctive normative action or situated normativity. Mary immediately and with instinctive fluency responds appropriately to Andra's distress (in a quite complex social context). Just as Wittgenstein's expert craftsmen are absorbed in their work, Mary is absorbed in her social engagements. Her action can be seen as an example of social instinctive normative action, because from a first-person perspective Mary's response to Andra is an instance of 'blindly' acting in accordance with rules of social interaction.

What we would like to understand in particular is what happens when an individual switches adequately yet unreflectively from doing one thing to doing another. In the case of Mary this means switching from a readiness for continuing a cheerful conversation to a readiness for comforting Andra. As we will see, the notion of valence developed by Varela and Depraz will help us come to grips with this question.

\section{Directed discontent in everyday engaged reflection}

We would like to present another Wittgensteinian example of instinctive normative action in everyday life. In his Philosophical Investigations, Wittgenstein describes how we seek the right word:

How do I find the 'right' word? How do I choose among words? Without doubt it is sometimes as if I were comparing them by fine differences of smell: 
That is too....., that is too.....,- - this is the right one.-But I do not always have to make judgments, give explanations; often I might only say: 'It simply isn't right yet'. I am dissatisfied, I go on looking. At last a word comes: 'That's it!' Sometimes I can say why. This is simply what searching, this is what finding, is like here. (Wittgenstein 1953, p. 218)

The first of Wittgenstein's descriptions of what could happen when one chooses a word - for example judging one as too strong and another as too weak-is what we call "engaged reflection". In the second of his descriptions appreciation plays a larger role. In both cases we continue searching until finally we find a word that satisfies us. ${ }^{4}$ Just as in the case of the architect presented in the introduction, the related phenomena of correctness (normativity) of the "object" (a word in the context of a sentence and a text) and experienced (directed) discontent are encountered in this type of everyday expertise (Rietveld 2004).

Directed discontent can here be seen as the tension that draws us to the right word for this sentence in this text:

'What is in my mind when I say so and so?' I write a sentence. One word isn't the one I need. I find the right word. 'What is it I want to say? Oh yes, that is what I wanted.' The answer in these cases is the one that satisfied you [...] (LA, p. 18, our italics).

Similarly, such tension can move an architect to find the right name for his studio or for the park he is designing.

When we seek the right word, we do not try words at random but improve stepby-step or by going back and forth. Afterwards, the word that is accepted as correct is characterized as the word that we were looking for all the time. The relation between the experience of zero discontent and the object, the right word for us in its context, is an internal relation (cf. Rietveld 2008b). ${ }^{5}$ The fact that in this example of everyday expertise we are directed primarily at our thoughts and/or words, shows that directed discontent can function with respect to various types of acts, including pre-reflective and somewhat more reflective ones.

To sum up, directed discontent is not only relevant for understanding the unreflective activities of craftsmen at work, but also for understanding at least some types of everyday expertise, such as everyday social interaction and seeking the right word. Also here the individual's experience of an object/person in context motivates a reaction of appreciation and improvement.

The case of seeking the right word shows that directed discontent, which is a paradigmatic form of situated normativity, plays a role not only in unreflective action but also in engaged reflection. A better understanding of directed discontent, or more in general lived normativity, will therefore further not only our understanding of perception and unreflective action, but also of (at least certain types of) reflection.

\footnotetext{
${ }^{4}$ Note that in this case it is implicitly assumed that the person cares about finding the right word.

${ }^{5}$ In an internal relation the relata belong together in an intrinsic way. This internal necessity is of a normative nature. 'Grammatical relation' is another term Wittgenstein uses for internal relation (cf. Moore 1954, p. 316).
} 
Again, we insist that to fully understand episodes such as those described above, one needs more perspectives than solely that of philosophy/phenomenology. More specifically, in this paper we attempt to make a case that neuroscience and psychology can be of much added value when trying to come to grips with the complex phenomenon of instinctive normative action. Before pursuing that path, however, we would like to discuss some methodological issues.

\section{Methodological note on integrating perspectives}

Philosophy and the sciences of psyche and brain

Contrary to what many might presume when neuroscience and philosophy are combined, our aim here is not to reduce instinctive normative action to neurophysiology. In fact, we do not believe that such a reduction would even be possible. Given the constitutive role of the socio-cultural practices $^{6}$ in which the actions that we describe in this paper necessarily take place, conceptually (this type of) normativity cannot be reduced to the neurological level in the single individual. Such a reduction would neglect the communal context in which the individual's action participates and without which we could not understand what, for instance, a certain neural activation pattern means. Moreover, a reduction to neurophysiology would neglect the lived normativity that is experienced by the person who feels directed discontent.

Hence, our aim is to make the phenomenon of instinctive normative action accessible to other perspectives that are complementary to the philosophical/ phenomenological. This is important because it is only through integration of the findings of various disciplines that we can achieve a thorough understanding of the complex phenomenon of instinctive normative action (Rietveld 2008c). These perspectives should certainly not be seen as opposing or competing with the philosophical/phenomenological ones. A basic assumption of our endeavor is the idea that the philosophical method known as phenomenology studies phenomena that are part of nature (for arguments see Gallagher and Zahavi 2008, p. 30). In other words, we assume that phenomena such as instinctive normative action can also be investigated by empirical scientists. Why is this important? Making it accessible to empirical research prepares the ground for an accumulation of understanding across disciplines, or so we hope.

\section{From Wittgenstein to Varela and Depraz}

As mentioned in the introduction, this paper builds on two (philosophical) threads: Wittgenstein's conception of directed discontent, and Varela and Depraz' analysis of valence. Our integration of these two suggests an interesting route for further research.

\footnotetext{
${ }^{6}$ See "Neurophenomenology and dynamical systems theory: a brief introduction" and section 5.3 of Rietveld (2008b) for arguments for this claim.
} 
Wittgenstein describes how expert craftsmen act in accord with socially constituted norms, "instinctively", without deliberation. We have seen that the phenomenon of directed discontent sheds light on such "blind" rule following. Throughout his analysis, Wittgenstein (LA) operates on a narrative time-scale, on which events take place that take at least several seconds to unfold.

Varela and Depraz (2005), on the other hand, aim to give a phenomenological analysis of our first-person experience when a certain aspect of a situation first affects us. In contrast to Wittgenstein, they do not employ a narrative (macro) timescale in their descriptions of instinctive normative action. Instead, their analysis concerns a micro-timescale, on which phenomenological experiences unfold and physiological processes take place that last up to about $1500 \mathrm{~ms}$.

This shift in perspective has an important consequence. In Wittgenstein's account, the experience of directed discontent appears to be an immediate event. However, it is one of the central outcomes of the analysis of Varela and Depraz (and one that is intrinsically tied to this shift in time-scale) that affects such as directed discontent develop in (micro-) time. In the next section we will clarify their methodology, because we make such extensive use of their approach.

\section{Neurophenomenology and dynamical systems theory: a brief introduction}

The methodology favored by Varela and Depraz is known as 'neurophenomenology'. Within that framework experiential invariants obtained via phenomenological analysis and first-person reports (typically of trained subjects) are used to constrain the analysis of neuroimaging data. With their phenomenological analyses Varela and Depraz (2005) aim to contribute to the empirical investigation of certain phenomena that play an important role within the phenomenological tradition (e.g. valence). The goal of this section is not so much to promote this method (since we would like to invite contributions from many different and complementary perspectives and not limit this invitation to one research paradigm), but rather to introduce some influential and useful ideas on the dynamics of brain and experience. A global understanding of neurodynamics is important because the proposal that we will make in "A strategy for investigating instinctive normative action empirically" is primarily relevant for empirical researchers that use the toolkit of non-linear dynamic systems theory.

Neurophenomenology is a research strategy in cognitive science that has been developed in order to reciprocally elucidate neuroscientific data (hence "neuro") and descriptive first-person reports the interpretation of which is informed by phenomenological analysis (hence "phenomenology") (Varela 1996; Thompson 2007). If necessary for the experiment, subjects can be trained in advance to improve their ability to describe specific elements of their first-person experience. ${ }^{8}$ So-called "non-linear dynamic systems theory" (henceforth: "dynamic systems theory") provides a conceptual framework and the mathematical tools for the research

\footnotetext{
$\overline{7}$ See for example Varela (1996) for an introduction to the neurophenomenological method.

${ }^{8}$ See Lutz (2002) for a discussion of an experiment (Lutz et al. 2002) in which subjects were trained.
} 
program of neurophenomenology. ${ }^{9}$ The aim of neurophenomenologists is to realize an integration of phenomenological analysis of experience and empirical work in neuroscience by using dynamic systems theory.

To avoid misunderstandings we should note that, even though we will focus on dynamic systems theory here because the contribution we make is primarily relevant for that field, it is not the case that we believe that this is the only relevant conceptual framework in neuroscience. Rietveld (2008c) has shown that other approaches in (cognitive) neuroscience can be fruitful as well in the analysis of situated normativity. As mentioned before, we believe that ultimately the (integrated) findings of various complementary perspectives are needed for a thorough understanding of skillful action.

Dynamic systems theory is used in the study of processes of self-organization. This phenomenon occurs when a large amount of small-scale processes come to run synchronously and therewith constitute a pattern on a larger scale (cf. Keijzer 2001, p. 201; Kelso 1995).$^{10}$ Dynamic systems theory describes how global order (a pattern) emerges from the collective action of a large amount of interacting components (Varela 1999b). Such a pattern-i.e., the collective action of the components - in turn restricts the degrees of freedom of the components of the system. (This is called "global-to-local influence" or "downward causality".) ${ }^{11}$ Varela and Thompson (2003) use the term "reciprocal causality" for this continuous reciprocal relation. They emphasize that the global or macroscopic order that emerges from the non-linearly interacting local components has its own intrinsic

\footnotetext{
${ }^{9}$ See for example Kelso (1995) for an introduction to dynamic systems theory that also discusses the dynamics of the brain and its relation with action. For more on dynamic systems theory see Port and Van Gelder (1995), Thelen and Smith (1994), Juarrero (1999), Freeman (2000a, b), Thompson (2007), and Friston $(1997,2000)$.

${ }^{10}$ Fred Keijzer explains clearly how self-organized patterns may emerge, for example in the brain: 'Christiaan Huygens discovered in 1665 that two pendulum clocks, hanging on a common support, tend to synchronize [...] When hung more widely apart, the clocks lose this perfect synchrony. This mutual influence of the two separate oscillators is called coupling. In this case only two oscillators were present, but it is also possible to have a large group of coupled oscillators, such as a swarm of fireflies or a collection of neural elements which show individual oscillatory activity. In a larger system of coupled oscillators interesting things can happen. Because of the mutual influence of the individual oscillators, global synchronization can occur at a much larger temporal scale than the cycles of the individual oscillators. The system as a whole can show large-scale order [...]' (Keijzer 2001, p. 201).

${ }^{11}$ Varela and Thompson (2003) use the term 'downward causation' to characterize the influence of the organization of the whole with respect to its components, but Thompson (2007) notes that "downward" is a tricky metaphor because we should not think in top-down terms but realize that 'the whole [complex] system moves at once' (Thompson 2007, p. 426). He explains that global-to-local influence or downward causation is a form of "system causation", a notion Searle describes as follows: "The right way to think of this is not so much "top down" but as system causation. The system, as a system, has causal effects on each element, even though the system is made up of these elements.' (Searle 2000, p. 17, as quoted by Thompson 2007, p. 426). Thompson suggests that the organization of the system as a whole restricts the degrees of freedom of the system's parts: '[Whole-to-part influence in complex systems theory] is therefore not an external force that acts on something, but an interconnectedness or relatedness among processes. This interrelatedness structures the context and background of local interactions, such that certain kinds of events can take place that otherwise would not occur' (Thompson 2007, p. 427). Kim, among others, has argued that downwards causation is an incoherent notion (see e.g. Kim 1999). Bitbol (2004) and Thompson (2007, Appendix B, pp. 431-441) counter Kim's objections. For reasons of space and brevity, we will not delve too deeply into this matter, taking the notion not so much as a philosophical point of dispute, but rather as an empirical given with possible relevance to various philosophical issues.
} 
features, duration and domain of causal efficacy. ${ }^{12}$ This does not mean that the existence of the macroscopic order is somehow independent of the microscopic processes. The macroscopic order is the relation of the components; global-to-local influence is the influence on the system's individual components as it is exerted by the way in which the components of the system relate to each other (see e.g. Thompson and Varela 2001, p. 420; Thompson 2007, pp. 426-427).

Turning to the study of the dynamics of brain and experience, we find that the working hypothesis of Varela and Thompson (2003) is that a specific transient largescale neural cell assembly forms the basis of any emerging cognitive act, from sensorimotor activity to the recollection of a pleasant incident. ${ }^{13}$ Empirical data suggesting that the nervous-system transiently integrates the neural assemblies that are relevant to some activity have been gathered from a diversity of organisms - that is to say, that the nervous-system continually generates order (underlying a specific cognitive act, such as a perception; cf. Varela 1999a, b; Varela et al. 2001; Rodriguez et al. 1999). A moment of conscious experience is conceptualized by Varela and Thompson (2003) as an emergent phenomenon of a collection of active neurons on the macroscopic level (cf. Panksepp 2005). ${ }^{14}$ As such, they hypothesize, experience can exert its influence on the activity of different smaller neural networks. In that way macroscopic patterns of activity in the brain can have global-to-local causal efficacy on various distributed neural assemblies, which are actively involved in bringing about some action.

Such theoretical considerations by themselves do not guarantee the fertility of the scientific methodology under discussion; empirical data are needed to convince people of its value. Neurophenomenological research in the study of perception (Lutz 2002) and epilepsy (Le Van Quyen et al. 1997) ${ }^{15}$ provide some illustrations of the concrete results that this research program might be able to realize (cf. Thompson 2007). To further clarify the neurophenomenological method and its ideas on the dynamics of brain and behavior we will here focus on the study of epilepsy. ${ }^{16}$

Observations indicate that in many cases epileptic seizures are preceded by changes that are experienced by the patients and that are perceptible in their neural dynamics. ${ }^{17}$ About $50 \%$ of all epilepsy patients experience 'warning symptoms', varying in time from several hours to a couple of minutes before the seizure. Analyses of patients' brain activity, carried out with the mathematical and conceptual apparatus of dynamic systems theory, point out that it is possible to detect preseizure activity in the neural dynamics several minutes before a seizure takes place.

Moreover, Le Van Quyen and Petitmengin (2002) give examples of both upward and of downward causality. Local neuronal activity at the level of an epileptogenic

\footnotetext{
${ }^{12}$ Naturally, this does not imply that they take all emergent processes to have downward causal efficacy.

${ }^{13}$ Up till now it belongs to the hypotheses that changes in synchronization patterns cause changes in consciousness or in behavior; only correlations have been found concerning this.

14 This does not mean that every macroscopic order in the brain necessarily correlates with a conscious experience.

${ }^{15}$ For a discussion see Le Van Quyen and Petitmengin (2002).

${ }^{16}$ For a discussion of the perception experiments by Lutz and colleagues, see Gallagher and Zahavi (2008).

17 The following account is largely derived from Le Van Quyen and Petitmengin (2002). For a discussion of the use of dynamic systems theory in epileptological research, see Stam (2003).
} 
zone has upward effects that result in changes in the individual's experience. ${ }^{18}$ In the reverse direction they hypothesize patients can sometimes consciously exert influence on local epileptic activity. Concerning this last and more controversial aspect of global-to-local influence, there exist several reports by patients as well as a number of clinical accounts (see Le Van Quyen and Petitmengin 2002; Penfield and Jasper 1954). Thompson describes the rationale for global-to-local influence thus:

The basic idea is that cognitive activity, which reflects large-scale integration in the brain, can affect local activity. For example, the subject can voluntarily affect local epileptic activity [...] (Thompson 2007, p. 63).

So according to Thompson (2007) it seems to be the case that the influence patients consciously exert can be characterized as causal global-to-local influence. ${ }^{19}$

Scientific proof of the possibility that epileptical activity not only influences mental competence, but that the reverse holds true as well, goes back to 1954, when Penfield and Jasper found support for this. Patients turned out to be able to prevent a seizure from happening by performing, for example, a difficult mathematical calculation, although their neural condition was such that it would normally have led to an epileptic seizure. ${ }^{20}$ More recently this was affirmed by Schmid-Schonbein (1998). Research by Le Van Quyen et al. (1997) indicates that also (active) perception may, at least in some cases, contribute to the voluntary control of seizures by global-to-local influence of the large-scale neural integration that is associated with the act of perception (cf. Varela and Thompson 2003). ${ }^{21}$

This concise introduction of the neurophenomenological method must suffice to show how according to Varela and Depraz (2005) research concerning the relationship between the dynamics of the brain and the dynamics of our experience could be related.

In the next section we will present our own contribution to the interdisciplinary investigation of directed discontent, namely that idea that valence is a precursor to

\footnotetext{
${ }_{18}$ Thompson described this local-to-global influence recently as follows: 'Focal epileptic seizures originate in specific parts of the cortex; they can remain confined to those areas or spread to other parts of the brain. Their clinical manifestations depend on the cortical area in which they originate, how widely they spread and how long they last. Local epileptic activity can [...] give rise to various kinds of mental experiences, such as visual of auditory illusions and hallucinations, and memory phenomena involving the vivid actual recall of a past event [...] Thus local neural activity at the level of an epileptogenic zone can produce large-scale effects, eventually influencing the global level of a moment of consciousness. This is a case of local-to-global emergence in the brain' (Thompson 2007, pp. 62-63).

${ }^{19}$ As mentioned in a previous note, here we will not elaborate our position in the philosophical debate regarding downward causation.

${ }^{20}$ Using the notion of global-to-local influence, Thompson gives the following interpretation of this phenomenon: "We can assume that such intervention is possible because the epileptogenic zones are embedded in a complex network of other brain regions that actively participate in the large-scale integration underlying cognitive acts. It seems reasonable to assume that these global patterns of integration can influence local events, including eventually the local epileptogenic zones, whose activity can thus be taken as an indication of the global influence.' (Thompson 2007, p. 63).

${ }^{21}$ Thompson summarizes the results and import of this experimental work thus: 'These findings suggest that the patient's act of perception contributed in a highly specific way to "pulling" the epileptic activities toward particular [kinds of dynamic patterns known as] unstable periodic orbits. Such global-to-local influence mobilized by cognitive activity might open up possibilities for cognitive strategies of control of epileptic seizures [...].' (Thompson 2007, p. 64).
} 
directed discontent. Below it will become clear that this notion of valence will help to investigate the first moments of the initiation of an instinctive normative action.

\section{A precursor to directed discontent: valence}

As indicated in the introduction, our main aim in this paper is to contribute to an understanding of what happens in situations of instinctive normative action. Our own contribution is primarily philosophical/phenomenological. Above directed discontent, for instance the architect's directed discontent in response to an incorrect door (in its context), was shown to be a paradigmatic form of instinctive normative action. We will now introduce a further example, namely that of a tailor at work. To distinguish this tailor from the one described by Wittgenstein (LA; Rietveld 2004, 2008b; Klaassen et al. 2006) we will refer to him as "the Brazilian tailor". We will describe this example on a narrative time scale, just like Wittgenstein did with his.

The Brazilian tailor is in a good mood when the fabric supplier arrives at his workspace. While chitchatting with this visitor, the tailor suddenly sees that the pattern of the fabric he just received is incorrect. In the wink of an eye his mood, attitude and expression change completely. Instead of continuing his conversation he is now fully concerned with obtaining the right fabric, that is to say the fabric with the right pattern.

If we want to gain a better understanding of the tailor's first-person experience of the alteration of his readiness to act which arises the moment he appreciates the incorrectness of the fabric he received, we need an analysis of the general characteristics of the moment at which an object emerges in awareness and triggers a change in one's flow of activity (Note that when he expresses his reaction of appreciation, the craftsman does not have to know the object in some propositional way to initiate an appropriate response.). Phenomenological analysis suggests that part of the process in which an affective experience is constituted takes place prereflectively and/or non-consciously (Varela and Depraz 2005).

In pre-reflective experience there is at least some minimal level of awareness of this constitution of meaning. Non-conscious (or unconscious) means that there is no awareness. Post hoc articulation of, or reflection on, non-conscious experience is not possible, but in the case of pre-reflective experience it is, albeit sometimes only minimally. This is called reflective consciousness or awareness. That is to say, such situations as just described generally affect us to some extent even before we have become reflectively conscious of it (cf. Merleau-Ponty 2002/1945; Rudrauf et al. 2003, p. 59).

Furthermore, as mentioned above, whereas on narrative time-scales it looks as if the experience of directed discontent is an immediate event, Varela and Depraz (2005) suggest that affective experiences such as this develop in (micro) time instead; i.e., that we are trying to understand processes rather than immediate events. (This does not imply that it is wrong to call directed discontent an immediate event in a narration. The micro-perspective offers another, complementary perspective, not a perspective that is better for all purposes.)

Varela and Depraz (2005) attempt to show that valence is an integral aspect of the first constitutive moments of any experience. When an event occurs, affect and 
movement are dimensions of our first response and this response already has an evaluative dimension to it. Moreover, following Husserl (1966, $\S 35$, p. 170; lectures given between 1920 and 1926) they say that such an experience has an "affective force" ("affective Kraft" in German) (Varela and Depraz 2005, p. 65).

Valence is related to the ability of the individual to determine quickly whether he or she should move towards or away from something that appears in his or her environment. This motion-affect is a kind of tension that can be characterized by both the (pre-reflective) affective experience of attraction/repulsion and the related behavioral tendency to move towards/away from the triggering feature of the situation. Other valence dimensions can be characterized as liking-disliking or pleasure-displeasure. Varela and Depraz insist that these polarities should not be understood too strictly, but that we should rather see them in terms of distinguishable global repertoires of possible actions. ${ }^{22}$ Valence, then, is the first relatively big (event-related) restriction of someone's room for maneuver in a particular situation. This analysis suggests that from the start, every quotidian experience of meaningful objects is value-laden.

There are several components that play a role in the temporal progression towards a more matured object-related affect, such as directed discontent. Thompson (2007) updates the components mentioned by Varela and Depraz (2005) and links them to emotion theory (Lewis 2005). Varela and Depraz clarify the components by means of concrete examples of momentary emotion episodes in which these can be discerned, including a situation of "averting the gaze" (Varela and Depraz 2005, p. 67). Here they follow Merleau-Ponty (1968, p. 28), who speaks about covering or shielding one's eye's in order not to see a danger. Varela and Depraz (2005, p. 69) describe some of the event-related movements in such a case as follows:

[I]n the gaze averting evocation, there are the eyelids closing, the hands that covers [sic] the eyes, the cringe of the neck as I turn the head, the posture of the mouth with a half-pronounced word that comes out as accompaniment. (Varela and Depraz 2005, p. 69).

Thompson's (2007, pp. 375-376) own averting-the-gaze example is an episode triggered by a stranger with an angry face who glares at one as one walks by. We quote Thompson at length, since what he presents is an important integration of insights from phenomenology and affective science:

Following Watt (1998) Varela and Depraz (2005) point to a number of concurrent components of affect in [...] momentary emotion episodes. [...]

* A precipitating event or trigger, which can be perceptual or imaginary [...]

* An emergence of affective salience, involving an evident sense of the precipitating event's meaning. In emotion theory, this aspect of emotion is described as reflecting an appraisal, which can take form before the experience of affect [...] Much of the appraisal will be prereflective and/or unconscious.

* A feeling-tone, described in psychology as having a valence or hedonic tone along a pleasant/unpleasant polarity.

\footnotetext{
${ }^{22}$ See Colombetti (2005) for a conceptual analysis of the notion of valence and a critical assessment of the traditional understanding of valence as a dichotomous notion.
} 
* A motor embodiment, in the form of facial and posture changes, and differential action tendencies or global intentions for acting on the world.

* A visceral-interoceptive embodiment, in the form of complex autonomicphysiological changes (to cardiopulmonary parameters, skin conductance, muscle tone, and endocrine and immune system activities).

Each of these five components can be discerned in [for instance] averting-thegaze examples [...] (Thompson 2007, p. 376, our insertions).

All these aspects develop in parallel, influence each other continually and in that way add to the emergence of an event-related affective expression and experience. Another example could be the Brazilian tailor's sudden change in expression, experience and action when he perceives that the pattern in the fabric delivered is incorrect. These changes are independent of reflection on the situation, and in that sense immediate.

Taken together, these components help to make clear that the first moment that something affects someone already involves movement, which is why motion-affect and affective behavior are apt characterizations of valence. This becomes manifest in, for example, the changed expression on the Brazilian tailor's face as well as in his attitude, but also in his anticipation of subsequent action as manifested in a readiness to act. That affective experience and bodily motion are interwoven in this way indicates that a better understanding of the relevant (neuro-) physiological processes and their unfolding in micro-time can add to a better understanding of the way in which our experience of an object as it first affects us progresses in micro-time. In other words, this interrelatedness of affective experience and bodily changes suggests a potential for cross-fertilization between phenomenology and the empirical sciences. $^{23}$

Although it is more basic, in the sense that there is less room for differentiation in experience as well as activity, valence resembles directed discontent. It too is a kind of reaction of appreciation experienced by the individual as a certain tension and tendency to move in a way that relieves this tension (cf. Varela and Depraz 2005, p. 70). Moreover, the intensity of it can vary from occasion to occasion (Varela and Depraz 2005, pp. 74-79). Yet, here it is important not to lose sight of the fact that valence involves a micro-perspective. For it is possible that what we experience and what develops on a micro-timescale constitutes only a brief and passing inclination for a person who was already absorbed in some activity or other. The impulse to act that valence implies, can be marginal and does not necessarily develop further to become the affect that we call directed discontent. In other words, on the microtimescale valence might be understood as an impulse for a full behavioral change, whereas on the narrative time-scale it might remain a small fluctuation in the flow of activity and experience of the individual in question.

It is crucial that the appreciation of an object or event (as being correct or incorrect, satisfactory or unsatisfactory, etc.) is already being formed on the microtimescale of valence. The architect's event-related valence will be very different

\footnotetext{
${ }^{23}$ Concretely this means that those interested in an interdisciplinary understanding of instinctive normative action can expect to find relevant insights in for example emotion psychology and its appraisal theory in particular (Frijda 2007; Lewis 2005; Sander and Scherer 2005).
} 
when he sees an incorrect door (in context) than when he sees a door that is exactly right in its context. His response is perceivable to others. In the situations of the craftsmen at work, social norms concerning appropriate action are already being reconfirmed (or not) at the very moment at which we speak of valence. Therefore we wish to suggest that valence, as a precursor to directed discontent, can be seen as the most basic moment at which situated normativity becomes perceptible. ${ }^{24}$ Valence is in these cases of instinctive normative action not some marginal fluctuation but the earliest integrated action tendency of an individual who is developing an adequate response to the situation. In other words, we can understand the person's experience and expression of (directed discontent-preceding) valence as the most basic form of instinctive normative action. In the next section we will use this insight to develop a strategy for empirical investigation of this type of action. Before going there, however, let us briefly see what this analysis means for one of the cases we discussed earlier.

Returning to our example of instinctive normative action in everyday social interaction we borrowed from Klaassen (2006), it can be argued that when investigated on a micro-timescale, it is plausible that Mary's first response to Andra's expression is non-conscious or pre-reflective. Just as in the example of the Brazilian tailor discussed above, Mary is probably affected by the situation before she has become reflectively conscious of how Andra feels. That this is a case of motion-affect is clear if we focus on, for instance, the changes in her facial muscles, which underlie Mary's change in expression, or on her initiation of a comforting action.

With regard to instinctive normative action the hypothesis is that the individual's embodied responsiveness to possibilities for action changes unreflectively and that the two relevant stages in this process are the emergence of valence and directed discontent, respectively. When Mary perceives Andra's expression, the development of valence already implies anticipation on several appropriate possible actions, whereas the route to other (inappropriate) possibilities for action is cut off. (And what is more, these inappropriate ways of action do not attract the skillful individual.)

\section{A strategy for investigating instinctive normative action empirically}

The aim of this section is to make the question of 'what happens when a skilled individual acts correctly with instinctive ease?' better accessible to empirical investigation. We will do so by exploiting the ideas that directed discontent is a paradigmatic expression of instinctive normative action and, moreover, that valence is a precursor to directed discontent.

What can we say of the micro-temporal developmental trajectory from valence to a fully developed affect? From a third-person perspective, we can observe that in general the emergence of a (cognitive) act is characterized by synchronous activity ('phase synchronization') or large-scale integration of a diversity of distributed brain regions (Varela and Thompson 2003). What we find here is a complex process of integration of several parts of an organism, which happens by way of self-

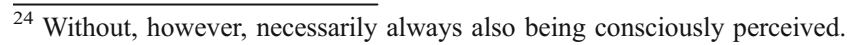


organization (see "Neurophenomenology and dynamical systems theory: a brief introduction").

Concerning the first-person perspective we can discern (at least) three stages:

1. Valence: the individual's first global readiness to act in response to a precipitating event. It can be characterized by tension, attraction or repulsion;

2. Directed discontent: reflects a more differentiated yet still unreflective appreciation of the situation and can be characterized by lived normativity and readiness for or initiation of a particular course of action;

3. Fully developed emotional experience: fully-fledged emotion with a reflective character.

This schematization suggests that directed discontent is to be found somewhere in between valence and a fully-developed emotional experience. Varela and Depraz (2005) distinguish globally between non-conscious, pre-reflective and reflective phases in the progression towards a fully developed emotion (Varela and Depraz 2005, pp. 70-71). Of these directed discontent is certainly characterized best as prereflectively experienced affective behavior, but sometimes it may be on the border of reflectivity.

If we consider the craftsman, the progression from valence to directed discontent can be understood by looking at the initiation of an adequate response to the situation. The tailor at work continually appreciates aspects of the objects he is working on. What he perceives as relevant can not be separated from his capacities, the object in its environment, his current task, available time and resources, and so on. Relevant aspects of the situation touch him and demand a reaction, whereas irrelevant aspects are ignored. The emergence of valence and directed discontent are two relevant stages in the process of initiating instinctively a (not the!) correct action in the situation. When the Brazilian tailor sees the fabric with the wrong pattern, the development of valence already implies anticipation of a certain region of the field of possible actions, whereas the route to other regions is cut off. That directed discontent unfolds in time is manifested by the potential action that the craftsman in fact prefers. In other words, when valence emerges, this is a first step on a path to a somewhat later and more articulated appreciative reaction. If movement at the most basic level of valence did not involve anticipation of correct action possibilities but also of incorrect ones, the craftsman could not act correctly immediately, as he in fact does.

The question of 'what happens when a skilled individual acts correctly with instinctive ease?' ran ahead of the possibility to examine aspects of such instinctive normativity in action empirically. Given the present state of neurodynamics this question is too complex, since we are dealing with a phenomenon that is difficult to examine, certainly neuroscientifically. This is connected with two things. First, there is the 'richness' of the phenomenon-recall all the relevant features of such situations where we speak of instinctive normative action. Second, the duration of such situations on the narrative time scale creates a difficulty for investigating the neurodynamics.

With respect to the first, in a situation of instinctive normative action we are concerned with whole individuals who take broad (social) contexts into account. Such situations involve affective, as well as behavioral aspects, a process of skillful 
attunement to relevant aspects of the complex situation, within a socio-cultural practice. Dealing adequately with this contextuality is a challenge for an experimental design. We do not want to claim that a focus on valence will take away this challenge. However, this is not unique to the case at hand. It is a challenge that is familiar to neuroscience more broadly and urgently needs to be addressed by empirical scientists and neuroscientific methodologists.

Concerning the second a practical problem arises. Phase-space techniques, which are one of the preferred mathematical tools of the neurodynamical approach for the analysis of nonlinear brain processes, are less well suited for processes that last over several seconds, according to Le Van Quyen (2003, pp. 72 \& 85). This makes the self-organizing neurodynamics underlying situations of instinctive normative action as described on the narrative time scale very hard to examine with the current toolset of the dynamical approach. ${ }^{25}$ However, if Le Van Quyen (2003, pp. 72 \& 85) is right that phase-space techniques are good for the analysis of processes that last several hundreds of milliseconds (ibid.), then this would fit well with the valence-related events that unfold on a micro-timescale.

However, with the concept of valence in hand a research strategy can now be formulated. Valence makes it possible to reformulate our question as follows: What happens in the first few hundred milliseconds of the development of directed discontent?

This question can probably be examined more easily. "Probably" because it need not diminish the need for innovative experimental design for dealing with the issue of context sensitivity (it is an open empirical question whether it will), but at least it seems to avoid the second of the two above-mentioned difficulties. On the basis of the preceding phenomenological analysis we can expect that in case of the craftsman's response to the incorrect object there is an impulse towards correct action even at the early moment when valence has developed. For as previously suggested, the person's experience and expression of (directed-discontent preceding) valence is the most basic form of instinctive normative action. The moment valence has developed, the individual is ready for certain types of responses but not for others and in that sense we (as observers) can speak of an anticipation of a range of appropriate possible actions. On the basis of the preceding it is furthermore to be expected that at this moment in (micro-) time such integration has taken place that we can speak of the individual's attraction or repulsion. This can be described from the perspectives of first-person experience, neurophysiology, emotion expression, and action.

We do not observe directed discontent until at least a few hundred milliseconds later, namely when he or she has initiated some act or other, or when his or her expression has become more articulate. Yet, the valence that arises early on, occurs in the context of the development of this directed discontent. Of course, it would still

\footnotetext{
${ }^{25}$ Le Van Quyen notes that whereas there is relative stability of significant factors during a short episode, complex stochastic processes in the brain come to play a role when the temporal scale expands to encompass several seconds and there emerges a 'disorganized complexity [...] because a system has a larger number of significant components that exhibit a high degree of random behavior [...]' (Le Van Quyen 2003, p. 72). We called the problem of duration a "practical problem" because Le Van Quyen (2003) suggests that progress in quantitative methods may one day provide neurodynamical researchers tools to properly describe systems that are characterized by such stochastic randomness.
} 
take some effort to develop this modified question into a concrete proposal for empirical research and non-philosophical expertise would have to be involved and take the lead in this, but it does seem to make the issue amenable to empirical investigation.

An important body of literature, which shows that cognitive neuroscience is able to generate interesting results on a micro-time scale, is that on the neural basis of 'adaptive action control' (Brown and Braver 2005; Ridderinkhof et al. 2004; Rushworth et al. 2004, 2005). When an action's outcome is worse than expected, for instance following a wrong response, according to an influential theory by Holroyd and Coles (2002), a negative reinforcement learning signal ('reward prediction error') is conveyed to the medial frontal cortex (dorsal anterior cingulate cortex) via the midbrain dopamine system (ventral tegmental area). ${ }^{26}$ They suggest that the impact of this pause in the dopaminergic projection on dorsal anterior cingulate activation is expressed in an electro cortical brain potential known as the Errorrelated negativity (ERN/Ne or informally as the 'Oh shit potential'). When things go worse than expected, the ERN is seen as a prominent and negative deflection of the event related potential (ERP) in the scalp electro-encephalogram (EEG).

The ERN occurs very rapidly: it peaks between 50-120 ms after the onset of an incorrect response. (This is often fast enough to correct behavior on the fly.) While the size of the ERN does not correlate with explicit awareness of response errors, a somewhat later positive ERP component, the Pe, has been associated with explicit awareness of the error (Nieuwenhuis et al. 2001, Lewis and Todd 2005). The Pe typically reaches maximum amplitude between 300 and $500 \mathrm{~ms}$ after an erroneous response and is thought to reflect the motivational significance of the error (Overbeek et al. 2005).

It is an open question how these findings relate to the phenomenon of valence, but the first attempts to integrate these results with work in affective science and the dynamics of brain and experience have been made already. Marc Lewis (2005; Lewis and Todd 2005) has presented an ambitious theory on the neurodynamics of emotional appraisal that aims to integrate insights from phenomenology, the cognitive neuroscience of adaptive action control, and dynamic systems theory (see Rietveld 2008a for a detailed discussion). This integration is possible because both Lewis and the cognitive neuroscientists mentioned above, such as Overbeek and colleagues (2005), are interested in how bodily evaluations (or in Lewis' terms 'appraisals') of the significance of events can, within a split second, lead to adaptive actions (or readiness for adaptive actions). Lewis and Todd's (2005) hypothesis is that a perturbing event leads to self-organizing dynamics in the brain. More in particular, they suggest that variations in the extensiveness of the self-organizing neural network (integrating more and more cortical areas with the brain stem, hypothalamus and limbic system) underlie the various phases of emotional episodes.

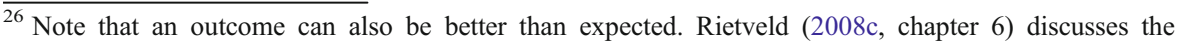
broader context of reward-based learning in which the reinforcement-learning signal plays a role.
} 


\section{Concluding remarks}

In this paper we have, firstly, tried to illustrate the width of the domain of application of the notion of instinctive normative action and, secondly, to make this complex phenomenon better accessible to empirical research. It was suggested that we direct our attention to directed discontent in order to get a hold on this phenomenon, as directed discontent is a paradigmatic form of instinctive normative action. Then it was demonstrated that by shifting from macro- to micro-timescale it becomes possible to pursue the question of "what happens when a skillful individual acts correctly with instinctive ease', by formulating a more restricted question, namely, 'what happens in the first few hundred milliseconds of the development of directed discontent'. We have tried only to sketch a strategy for answering this question.

In this sketch it was suggested that instinctive normative action can be divided up into the episodes of valence and directed discontent (the former being an intimately related precursor to the latter). Multiple perspectives were proposed that can be taken on both of these: phenomenology, psychology, neurodynamics and (third-person descriptions and analysis of) action amongst others. Each of these perspectives requires its own method of research, and each has its own limitations, advantages and disadvantages. But they are complementary and ultimately we need all of them for a better understanding of directed discontent and unreflective action. For instance, the notion of valence, which is useful for this purpose, has roots both in phenomenology and psychology. A phenomenology of the feelings of normative constraint could benefit from the idea that valence plays a crucial role in the first moments of our response to a meaningful event. This directs the phenomenologist's attention to the important links between normativity, motion-affect and feelings of normative constraint.

Not only our understanding of the normativity of expert action but also that of many everyday social situations of adequate unreflective action and of at least certain types of engaged reflective action could potentially benefit from phenomenological and empirical investigations of the microdevelopment of motion-affect. The introduction of the notion of valence as a precursor to directed discontent invites both phenomenological and neuroscientific research into the nature of instinctive normative action.

The choice of the relevant time-scale demands attention. With a decrease in duration, the articulation of first-person experience becomes harder. With an increase in duration the reverse holds but the preferred toolset of neural dynamics cannot be used. Valence, however, seems to offer a promising perspective, as it seems probable that both phenomenologically and neuroscientifically interesting results can be obtained concerning this. To sum up, this motion-affect embodies the individual's earliest normative appreciation of an event in the particular situation.

This invitation to investigate situated normativity in everyday life will hopefully not only be attractive to phenomenologists, emotion psychologists and cognitive neuroscientists, but also to neurophenomenologists. In response to Lewis' (2005), Colombetti and Thompson (2005, p. 201) claimed that "neurophenomenology provides a promising research program for exploring and testing Lewis's hypotheses about synchronous/asynchronous interactions across gamma and theta frequency bands in corticolimbic systems [...]". Two challenges for neurophenomenological investigations of the kind suggested by them will be to do justice to context 
sensitivity and the richness of experiences of lived normativity. But the most important challenge for neurophenomenology is now actually to do the experiments on a micro-timescale that can contribute to understanding valence better. This ambitious method is still in urgent need of empirical data to convince people of its value. $^{27}$

Acknowledgements We would like to thank Boudewijn de Bruin, Paul Voestermans and the anonymous referees for feedback on an earlier version of this paper. We owe special thanks to Martin Stokhof. Erik Rietveld did part of the research for this paper during his stay as a Fellow in Philosophy at Harvard University. His research visit was funded by NWO 'Netherlands Organisation for Scientific Research'. He would like to express his gratitude for awarding this "Rubicon" grant.

Open Access This article is distributed under the terms of the Creative Commons Attribution Noncommercial License which permits any noncommercial use, distribution, and reproduction in any medium, provided the original author(s) and source are credited.

\section{References}

Bitbol, M. (2004) Downward causation: Concept and experience. Presented at conference 'From Autopoiesis to Neurophenomenology: A tribute to Francisco Varela', Paris, June 18-20, 2004.

Brown, J. W., \& Braver, T. S. (2005). Learned predictions of error likelihood in the anterior cingulate cortex. Science, 307, 1118-1121.

Colombetti, G. (2005). Appraising valence. Journal of Consciousness Studies, 12, 103-126.

Colombetti, G., \& Thompson, E. (2005). Enacting emotional interpretations with feeling. Behavioral and Brain Sciences, 28, 200-201.

De Lara, P. (2003). Wittgenstein as anthropologist: the concept of ritual instinct. Philosophical Investigations, 26(2), 109-124.

Freeman, W. J. (2000a). How brains make up their minds. New York: Columbia University Press.

Freeman, W. J. (2000b). Neurodynamics: An exploration in mesoscopic brain dynamics. London: Springer.

Frijda, N. H. (2007). The laws of emotion. Mahwah, NJ: Erlbaum.

Friston, K. J. (1997). Transients, metastability, and neuronal dynamics. Neuroimage, 5, 164-171.

Friston, K. J. (2000). The labile brain. II: transcients, complexity and selection. Royal Society, 355, 237252.

Gallagher, S. (2003). Phenomenology and experimental design. Journal of Consciousness Studies, 10(910), 85-99.

Gallagher, S., \& Varela, F. (2003). Redrawing the map and resetting the time: phenomenology and the cognitive sciences. Canadian Journal of Philosophy, 29, 93-132.

Gallagher, S., \& Zahavi, D. (2008). The phenomenological mind. New York: Routledge.

Holroyd, C., \& Coles, M. (2002). The neural basis of human error processing. Reinforcement learning, dopamine, and the error-related negativity. Psychological Review, 109, 679-709.

Husserl, E. (1966). Analysen zur Passiven Synthesis (Hua XI). Dordrecht: Kluwer.

Juarrero, A. (1999). Dynamics in action: Intentional behavior as a complex system. Cambridge, MA: MIT. Keijzer, F. (2001). Representation and behavior. Cambridge, MA: MIT.

Kelso, J. A. S. (1995). Dynamic patterns: The self-organization of brain and behavior. Cambridge, MA: MIT.

Kim, J. (1999). Making sense of emergence. Philosophical Studies, 95, 3-36.

\footnotetext{
${ }^{27}$ For those who are skeptical about the potential of integrating the tools of neurodynamics and empirical research, it is important to note that neurophenomenology is not the only way to integrate insights from phenomenology and neuroscience. Another methodological option is what Gallagher (2003) calls "frontloaded" phenomenology. Here insights from phenomenology, for instance on the role of valence, can inform the design of neuroscientific experiments. This method is more traditional than neurophenomenology and neither requires the training of subjects nor the use of neurodynamics.
} 
Klaassen, P. (2006). Experience and social norms in folk psychology-Wittgenstein meets neuroscience. In G. Gasser, C. Kanzian \& E. Runggaldier (Eds.), Cultures: Conflict-analysis-dialogue (pp. 306308). Kirchberg: ALWS.

Klaassen, P., Rietveld, E., \& Topal, J. (2006). Gesitueerde normativiteit: Van Wittgenstein naar neurofenomenologie. $A N T W, 98(1), 1-17$.

Le Van Quyen, M. (2003). Disentangling the dynamic core: a research program for a neurodynamics at the large-scale. Biological Research, 36, 67-88.

Le Van Quyen, M., \& Petitmengin, C. (2002). Neuronal dynamics and conscious experience: an example of reciprocal causation before epileptic seizures. Phenomenology and the Cognitve Sciences, 1, 169180.

Le Van Quyen, M., Adam, C., Lachaux, J.-P., Martinerie, J., Baulac, M., Renault, B., et al. (1997). Temporal patterns in human epileptic activity are modulated by perceptual discriminations. Neuroreport, 8, 1703-1710.

Lewis, M. D. (2005). Bridging emotion theory and neurobiology through dynamic systems modeling. Behavioral and Brain Sciences, 28, 169-245.

Lewis, M. D., \& Todd, R. M. (2005). Getting emotional: a neural perspective on emotion, intention, and consciousness. Journal of Consciousness Studies, 12(8-10), 210-235.

Lutz, A. (2002). Toward a neurophenomenology as an account of generative passages: a first empirical case study. Phenomenology and the Cognitive Sciences, 1, 133-167.

Lutz, A., Lachaux, J.-P., Martinerie, J., \& Varela, F. J. (2002). Guiding the study of brain dynamics by using first-person data: synchrony patterns correlate with ongoing conscious states during a simple visual task. Proceedings of the National Academy of Sciences USA, 99(3), 1586-1591.

Merleau-Ponty, M. (1968/1964). The visible and the invisible (Lingis, A., trans.). Evanston, Illinois: Northwestern University Press.

Merleau-Ponty, M. (2002/1945). Phenomenology of perception (Smith, C., trans.). London: Routledge.

Moore, G. E. (1954). Wittgenstein's lectures 1930-33. Part II. Mind 63, pp. 289-316.

Nieuwenhuis, S., Ridderinkhof, K. R., Blom, J., Band, G. P., \& Kok, A. (2001). Error-related brain potentials are differentially related to awareness of response errors: evidence from an antisaccade task. Psychophysiology, 38, 752-760.

Overbeek, T. J. M., Nieuwenhuis, S., \& Ridderinkhof, K. R. (2005). Dissociable components of error processing: on the functional significance of the Pe vis-à-vis the ERN/Ne. Journal of Psychophysiology, 19(4), 319-329.

Panksepp, J. (2005). On the embodied neural nature of core emotional affects. Journal of Consciousness Studies, 12(8-10), 158-184.

Penfield, W., \& Jasper, H. (1954). Epilepsy and the functional anatomy of the human brain. Boston: Little, Brown.

Port, R. F., \& van Gelder, T. (eds). (1995). Mind as motion: Explorations in the dynamics of cognition. Cambridge, MA: MIT.

Ridderinkhof, K. R., Ullsperger, M., Crone, E. A., \& Nieuwenhuis, S. (2004). The role of the medial frontal cortex in cognitive control. Science, 306, 443-447.

Rietveld, E. (2004). Wittgenstein's directed discontent: Clarifying the roles of experience and appreciation in skillful coping. In J. C. Marek \& M. E. Reicher (Eds.), Experience and analysis: Papers of the 27th International Wittgenstein Symposium (pp. 306-308). Kirchberg am Wechsel: ALWS.

Rietveld, E. (2008a). The skillful body as a concernful system of possible actions: phenomena and neurodynamics. Theory \& Psychology, 18(3), 341-363.

Rietveld, E. (2008b). Situated normativity: the normative aspect of embodied cognition in unreflective action. Mind, 117, 973-1001.

Rietveld, E. (2008c) Unreflective action. A philosophical contribution to integrative neuroscience. $\mathrm{PhD}$ Thesis, University of Amsterdam, Amsterdam: ILLC Dissertation Series DS-2008-05.

Rodriguez, E., George, N., Lachaux, J.-P., Martinerie, J., Renault, B., \& Varela, F. J. (1999). Perception's shadow: long-distance synchronization of human brain activity. Nature, 397, 430-433.

Rudrauf, D., Lutz, A., Cosmelli, D., Lachaux, J.-P., \& Le Van Quyen, M. (2003). From autopoiesis to neurophenomenology: Francisco Varela's exploration of the biophysics of being. Biological Research, 36, 27-65.

Rushworth, M. F., Walton, M. E., Kennerley, S. W., \& Bannerman, D. M. (2004). Action sets and decisions in the medial frontal cortex. Trends in Cognitive Sciences, 8, 410-417.

Rushworth, M. F., Kennerley, S. W., \& Walton, M. E. (2005). Cognitive neuroscience: resolving conflict in and over the medial frontal cortex. Current Biology, 15, R54-56. 
Sander, D., \& Scherer, K. R. (2005). Amalgams and the power of analytical chemistry: affective science needs to decompose the appraisal-emotion interaction. Behavioral and Brain Sciences, 28(2), 216217.

Schmid-Schonbein, C. (1998). Improvements of seizure control by psychological methods in patients with intractable epilepsy. Seizure, 7, 261-270.

Searle, J. R. (2000). Consciousness, free action and the brain. Journal of Consciousness Studies, 7, 3-22.

Stam, C. (2003). Chaos, continuous EEG, and cognitive mechanisms: a future for clinical neurophysiology. American Journal of Electroneurodiagnostic Technology, 43, 211-227.

Thelen, E., \& Smith, L. B. (1994). A dynamic systems approach to the development of cognition and action. Cambridge, MA: MIT.

Thompson, E. (2007). Mind in life: Biology, phenomenology, and the sciences of mind. Cambridge MA: The Belknap Press of Harvard University Press.

Thompson, E., \& Varela, F. J. (2001). Radical embodiment: neural dynamics and consciousness. Trends in Cognitive Science, 5(10), 418-425.

Varela, F. J. (1996). Neurophenomenology: a methodological remedy for the hard problem. Journal of Consciousness Studies, 3, 330-350.

Varela, F. J. (1999a). Ethical know-how: Action, wisdom, and cognition. Stanford: Stanford University Press.

Varela, F. J. (1999b). The specious present: A neurophenomenology of time consciousness. In J. Petitot, F. J. Varela, B. Pachoud \& J. M. Roy (Eds.), Naturalizing phenomenology: Issues in contemporary phenomenology and cognitive science (pp. 266-314). Stanford: Stanford University Press.

Varela, F. J., \& Depraz, N. (2005). At the source of time: valence and the constitutional dynamics of affect. Journal of Consciousness Studies, 12, 61-81.

Varela, F. J., \& Thompson, E. (2003). Neural synchrony and the unity of mind: A neurophenomenological perspective. In A. Cleeremans (Ed.), The unity of consciousness: Binding, integration and dissociation (pp. 266-287). Oxford: Oxford University Press.

Varela, F. J., Lachaux, J.-P., Rodriguez, E., \& Martinerie, J. (2001). The brain web: phase-synchronization and large brain integration. Nature Reviews Neuroscience, 2, 229-239.

Watt, D. F. (1998) Emotion and consciousness: Implications of affective neuroscience for extended reticular thalamic activating system theories of consciousness. Target Article, Association for the Scientific Study of Consciousness Electronic Seminar. Unpublished.

Wittgenstein, L. (1953). Philosophical investigations. Oxford: Blackwell.

Wittgenstein, L. (1978). Lectures on aesthetics. In L. Wittgenstein (Ed.), Lectures and conversations on aesthetics, psychology and religious belief (pp. 1-40). Oxford: Blackwell.

Wittgenstein, L. (1993). Cause and effect: Intuitive awareness. In J. C. Klagge \& A. Nordmann (Eds.), Philosophical occasions 1912-1951 (pp. 368-426). Indianapolis: Hackett. 